Témoigner Témoigner. Entre histoire et mémoire

Getuigen Revue pluridisciplinaire de la Fondation Auschwitz

$121 \mid 2015$

Violences radicales en scène

\title{
La mémoire de la bataille de Borodino
}

\section{Ilya Platov}

\section{OpenEdition}

\section{Journals}

Édition électronique

URL : https://journals.openedition.org/temoigner/3544

DOI : 10.4000/temoigner.3544

ISSN : 2506-6390

Éditeur :

Éditions du Centre d'études et de documentation Mémoire d'Auschwitz, Éditions Kimé

Édition imprimée

Date de publication : 1 octobre 2015

Pagination : 174-175

ISSN : 2031-4183

\section{Référence électronique}

Ilya Platov, "La mémoire de la bataille de Borodino », Témoigner. Entre histoire et mémoire [En ligne],

121 | 2015, mis en ligne le 01 octobre 2016, consulté le 04 février 2022. URL : http://

journals.openedition.org/temoigner/3544; DOI : https://doi.org/10.4000/temoigner.3544

Ce document a été généré automatiquement le 4 février 2022.

Tous droits réservés 


\title{
La mémoire de la bataille de Borodino
}

\author{
Ilya Platov
}

1 Symbole de la résistance patriotique à l'envahisseur, la bataille de Borodino est aussi l'une des plus sanglantes batailles des guerres napoléoniennes, et elle demeure aujourd'hui un grand symbole de l'identité russe. Le champ de Borodino lui-même devient le lieu où s'opère la transfiguration d'un lieu de carnage en lieu sacré du souvenir. Au XIX siècle, le souvenir de Borodino sert à exalter la réunion de l'Empire, du peuple et de la foi orthodoxe. En 1839, le premier grand monument est inauguré sur le champ de bataille à l'occasion d'une cérémonie commémorative en présence de l'empereur. Pour Nicolas $1^{\mathrm{er}}$, la fonction de la commémoration consiste à affirmer la grandeur et la supériorité morale et militaire de l'Empire russe en face de l'Europe, et le lien entre l'empereur, l'armée et l'Église orthodoxe. D'autre part, la mémoire officielle de la bataille de Borodino est étroitement associée à la ville de Moscou. La cathédrale du Christ Sauveur édifiée entre 1839 et 1883 est à la fois un lieu de culte et un musée de la guerre qui entretient la signification providentielle de la bataille et celle d'un événement décisif de l'histoire russe. À l'occasion du jubilé du centenaire de Borodino en 1912, le champ de bataille est transformé en un vaste ensemble commémoratif qui voit affluer officiels, pèlerins et touristes. Alliance franco-russe oblige, on préfère évoquer la victoire sur « Napoléon » plutôt que sur les « Français ». Les discours et les inscriptions sur les monuments évoquent avant tout les faits d'armes glorieux plutôt que la mort collective.

2 Malgré une brève éclipse après 1917, la légende de Borodino revient en force à la veille de la Seconde Guerre mondiale, et en 1960 la décision est prise de conférer au site de la bataille le statut de réserve nationale. Guerre sainte puisque combat pour le sol sacré de la patrie, Borodino est promue comme archétype de la guerre populaire au début de la Grande Guerre patriotique. Depuis les années 1980, les monuments de la période tsariste sont fidèlement reconstruits, et l'Église orthodoxe participe de nouveau aux commémorations. À Borodino, le culte des morts délivre toujours une injonction identitaire, et leur souvenir est évoqué dans le cadre d'une éducation politique. Le culte 
commémoratif se dédouble: d'un côté, la reconstitution toujours de plus en plus minutieuse contribue à la muséification du lieu et à sa transformation en site touristique, entraînant une mise à distance esthétique. Les reconstitutions historiques des batailles qui font partie des commémorations annuelles ont un parfum de nostalgie et comportent une dimension ludique évidente. Les Français sont désormais régulièrement présents aux commémorations annuelles; de l'autre côté, le rapprochement entre les guerres de 1812 et 1941-1945 contribue à entretenir la dimension sacrale du site. Au cours de la commémoration du bicentenaire de la bataille en 2012, le président Vladimir Poutine a évoqué la continuité entre les deux guerres "patriotiques", qui ont «décidé de l'avenir de la Russie, de l'Europe et du monde entier." À Borodino, les morts ont toujours une leçon à donner aux vivants, et l'entretien de la mémoire des combattants tombés sur le champ d'honneur est aujourd'hui interprété comme un gage de coexistence pacifique en Europe. Les morts des deux guerres patriotiques ont désormais un statut d'égalité dans la mémoire nationale et se portent garants de la continuité historique par-delà les ruptures historiques que la Russie a connues au cours du $\mathrm{XX}^{\mathrm{e}}$ siècle. La légende de Borodino achève ainsi de s'ériger en mythe de la nation, de la foi et du peuple.

\section{BIBLIOGRAPHIE}

« Autour de Guerre et Paix : la campagne de Russie », Cahier Léon Tolstoï, n²4, Michel Aucouturier (dir.), Paris, Institut d'Études slaves, 2013.

http://borodinoru.ru/ : tous les monuments de Borodino

www.borodino.ru : musée de Borodino

www.ambafrance-ru.org/Commemoration-de-la-bataille-de

\section{AUTEUR}

ILYA PLATOV

INALCO 